\title{
Sexual violence and abuse and the care programme approach
}

Charles G. D. Brooker, Karen Tocque, Martin Brown and Angela Kennedy

\section{Summary}

In 2008 it became policy that all those on the care programme approach were assessed for sexual violence/ abuse. The implementation of this policy was assessed 8 years on. The findings of a survey and data request to Health and Social Care Information Centre are disappointing. We argue that this important initiative needs to be reinvigorated.

\author{
Declaration of interest \\ None.
}

\section{Copyright and usage}

(c) The Royal College of Psychiatrists 2016.
Charlie Brooker (pictured) is honorary professor of criminal justice and mental health in the Centre for Criminology and Sociology at Royal Holloway, University of London. He was previously professor of mental health in SCHARR, University of Sheffield. Karen Tocque works in health intelligence through visiting professorships and social enterprise. She has a doctorate in epidemiology and expertise in applied public health research. Martin Brown was formerly mental health policy lead at the Department of Health and Director of the Northern Centre for Mental Health. He is now honorary professor in the Department of Nursing, University of York. Angela Kennedy is Service Lead for Tertiary Psychosis Team and Consultant Psychologist at Tees, Esk \& Wear Valleys NHS Foundation Trust.

Recent international research demonstrates that between 40 and $47 \%$ of attendees at a Sexual Assault Referral Centre are known to mental health services. ${ }^{1-3}$ The role of sexual violence and abuse has been also well documented in the aetiology of mental health disorders where there is an additive effect. ${ }^{4}$ For example, those subjected to extreme sexual violence are more likely to be: alcohol dependent, drug dependent, admitted to a psychiatric unit and to have attempted suicide. ${ }^{5}$

\section{Implementation of policy}

In 2008, in recognition of the impact of sexual violence and abuse on mental health, it became policy, that all those on the care programme approach (CPA) should be assessed by 'trained' mental health clinicians for their experience of sexual violence/ abuse. In 2008/9 a national training programme was piloted in eight mental health trusts. In the context of routine enquiry, and some 8 years on, it is pertinent to ask to what extent the CPA is being adhered to today in this regard. A national survey of mental health trusts, using freedom of information requests, was undertaken in 2015 in order to examine this. Providers were asked about clinical practice in relation to sexual violence/abuse and the CPA and a response rate of $79 \%$ was obtained. All trusts stated that they recorded whether routine enquiry took place but only $14 \%$ of trusts audited this activity $(n=5)$. One such reported audit examined ten admissions over a period of 1 week. The average proportion of staff reported to have been trained to undertake routine enquiry was $66 \%$ (range 35-100\%) with all trusts stating that such training was mandatory.

Data on routine enquiry was requested from the Health and Social Care Information Centre (HSCIC). This was the first ever request they had received on this topic. These data revealed that, in total, there were 335727 people on the CPA in England but whether routine enquiry had taken place was recorded for just $17 \%$ of this group (56914). Provider trusts can choose to submit data on this topic unlike other CPA items, which are mandatory to record. In 2014/15, over half of providers (57\%) chose not to submit data on the indicator (Fig. 1). For the 30 providers that did submit information the data field was only $41 \%$ complete. Only 11 trusts out of 53 returned full data on the abuse indicator.

It seems clear from the data presented that all impetus has been lost on the initiative that commenced in 2008 to establish routine enquiry as part and parcel of the CPA assessment. In the course of this project, the Department of Health was approached and asked whether routine enquiry in the CPA was still national policy. The Department of Health referred us to NHS England who in turn referred us back to the Department of Health. Both agencies could not answer our question. In this policy vacuum it is perhaps not surprising that providers' efforts are waning.

In the course of working on this project, a mental health service in Tees, Wear and Esk Valley was identified that has been making formal efforts to become 'trauma-informed'. The trauma-informed mental health service has been developed over the past 10 years and includes: the design of a specific pathway; staff training (including formulation, use of assessment measures

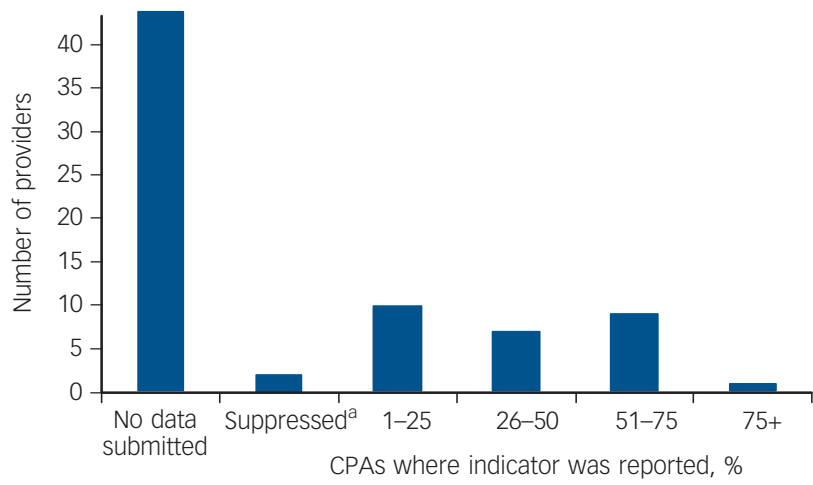

Fig. 1 The number of National Health Service mental health trusts that returned care programme approach (CPA) data to the Health and Social Care Information Centre (HSCIC) on the abuse indicator (2014/15).

a. The value for these providers was suppressed and all other numbers were rounded to the nearest five. 
and core skills); design of written guidelines and information sheets for service users, clinical staff and managers alike; and promotion and ownership by the Trust Board itself. Soft outcome measures revealed that the model, which specifically explored sexual violence/abuse, reduced staff sickness and decreased the use of 'as needed' medication and control and restraint. ${ }^{6}$ The use of outcome measures such as the Trauma Screening Questionnaire $^{7}$ revealed that $80 \%$ of those admitted had experienced trauma that was largely unresolved.

\section{Way forward}

Is it important that this area of practice is enhanced, and if so, how should improvements be made? First, the Department of Health and NHS England should agree under whose bailiwick this sits. Second, it should be a mandatory requirement that returns are made to the HSCIC on this area of the CPA as for other CPA indicators. Third, commissioners should be addressing shortfalls in staff training, which in some trusts are as low as $35 \%$. Finally, what role, if any should the Care Quality Commission (CQC) be playing? The CQC inspects in relation to four main key areas of enquiry: safety, effectiveness, caring and well-led. Under 'safety', the following indicator is outlined: are there reliable systems in place to keep people safe and safeguarded from abuse? Unless routine enquiry takes place how can patient safety be accurately assessed?
Charles G. D. Brooker, MSC, PhD, Royal Holloway, University of London, London; Karen Tocque, PhD, University of Chester, Chester; Martin Brown, University of York, York; Angela Kennedy, MSc, Tees, Esk and Wear Mental Health Trust

Correspondence: Charles G. D. Brooker, Centre for Criminology and Sociology, Royal Holloway, University of London, Egham Hill, Egham, Surrey TW20 OEX, UK. Email: charlie.brooker@rhul.ac.uk

First received 15 Apr 2016, final revision 15 Jun 2016, accepted 4 Jul 2016

\section{References}

1 Brooker C, Durmaz E. Mental health, sexual violence and the work of Sexual Assault Referral Centres (SARCs). J Forensic Leg Med 2015; 31: 47-51.

2 Bicanic I, Snetselaar H, De Jongh A, Van de Puttee E. Victim's use of professional services in a Dutch sexual assault centre. Eur J Psychotraumatol 2014; 5: 10.3402/ejpt.v5.23645.

3 Brown R, Du Mont J, Macdonald S, Bainbridge D. A comparative analysis of victims of sexual assault with and without mental health histories: acute and follow-up care characteristics. J Forensic Nurs 2013; 9: 76-83.

4 Jonas $\mathrm{S}$, Bebbington $\mathrm{P}$, McManus $\mathrm{S}$, Meltzer $\mathrm{H}$, Jenkins R, Kuipers $\mathrm{E}$, et al. Sexual abuse and psychiatric disorder in England: results from the 2007 Adult Psychiatric Morbidity Survey. Psychol Med 2011; 41: 709-19.

5 NatCen. Violence, Abuse and Mental Health in England (REVA Briefing 1). NatCen, 2015 (www.natcen.ac.uk/revabriefing1).

6 Brooker $\mathrm{C}$, Brown $\mathrm{M}$, Tocque $\mathrm{K}$, Kennedy $\mathrm{A}$. The care programme approach, sexual violence and clinical practice in mental health. J Forens Leg Med 2016; 43: 97-101.

7 Brewin CR, Rose S, Andrews B, Green J, Tata P, McEvedy C, et al. Brief screening instrument for post-traumatic stress disorder. Br J Psychiatry 2002; 181: $158-62$. 